\title{
Erratum to: White matter measures are near normal in controlled HIV infection except in those with cognitive impairment and longer HIV duration
}

\author{
Lucette A. Cysique ${ }^{1,2,3}$ • James R. Soares ${ }^{1} \cdot$ Guangqiang Geng $^{1} \cdot$ Maia Scarpetta $^{1}$. \\ Kirsten Moffat ${ }^{4} \cdot$ Michael Green $^{1} \cdot$ Bruce J. Brew ${ }^{2,3,5,6}$ - Roland G. Henry ${ }^{7}$. \\ Caroline $\operatorname{Ra}^{1,2}$
}

Published online: 28 July 2017

(C) Journal of NeuroVirology, Inc. 2017

Erratum to: J. Neurovirol

DOI 10.1007/s13365-017-0524-1

In the section "Statistical analyses"

Third indented paragraph line 3

$[\ldots]$ neurocognitively normal (NR normal; $N=36)[\ldots]$ and not 26 as reported.

\section{Corrections for Fig. 1}

The MD data for the HIV- and HIV+ data were erroneously inverted.
The CG (Cingulum) effect size was incorrect: it is -.13 rather than -.07 .

A new Fig. 1 appears below. These corrections do not affect any of the reported analyses and results because they are typographical and illustration errors.

The online version of the original article can be found at doi: http://dx.doi. org/10.1007/s13365-017-0524-1

Lucette A. Cysique

lcysique@unsw.edu.au

1 Neuroscience Research Australia, 139 Barker Street,

Randwick, NSW 2031, Australia

2 Faculty of Medicine, UNSW Australia, Sydney 2052, NSW, Australia

3 Peter Duncan Neuroscience Research Unit, St. Vincent's Applied Medical Research Centre, Darlinghurst 2010, NSW, Australia

4 Department of Imaging, St. Vincent's Hospital, Darlinghurst 2010, NSW, Australia

5 Department of Neurology, Sydney St. Vincent's Hospital, Darlinghurst 2010, NSW, Australia

6 Department of Immunology, Sydney St. Vincent's Hospital, Darlinghurst 2010, NSW, Australia

7 School of Medicine, Department of Neurology, University of California San Francisco, San Francisco, CA, USA 
FA
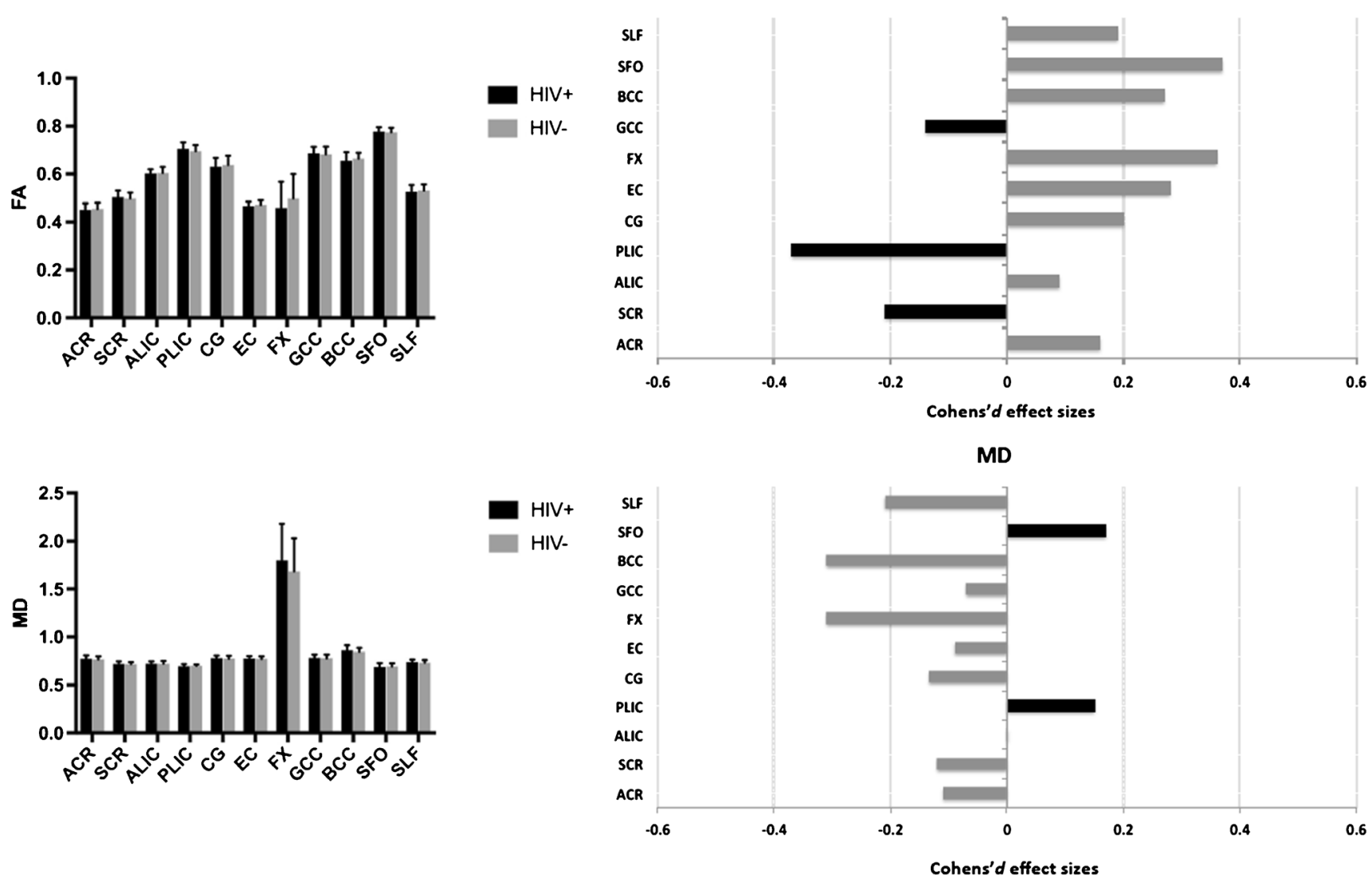

Fig. 1 